\title{
A Review of the Development of an Internet Delivered LL.M Program in the United States
}

William Byrnes

Texas A\&M University School of Law, williambyrnes@tamu.edu

Follow this and additional works at: https://scholarship.law.tamu.edu/facscholar

Part of the Legal Education Commons

\section{Recommended Citation}

Byrnes W H, 'A Review of the Development of an Internet Delivered LL.M Program in the United States', 2001 (3) The Journal of Information, Law and Technology (JILT).

This Article is brought to you for free and open access by Texas A\&M Law Scholarship. It has been accepted for inclusion in Faculty Scholarship by an authorized administrator of Texas A\&M Law Scholarship. For more information, please contact aretteen@law.tamu.edu. 


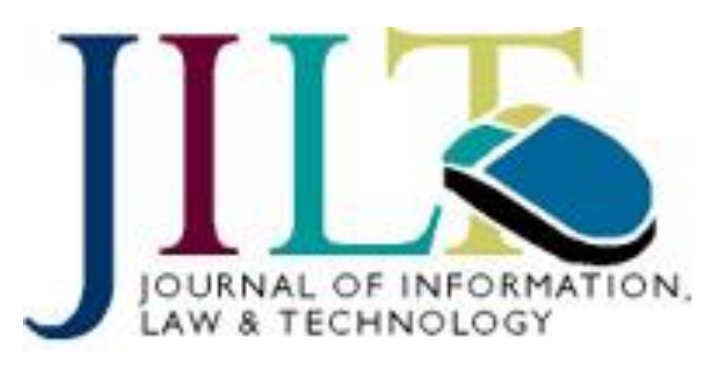

Journal of Information, Law and Technology

\title{
A Review of the Development of an Internet Delivered LL.M Program in the United States
}

\author{
Professor William H Byrnes, IV \\ Executive Director, LLM, International Tax Planning and \\ Offshore Financial Centers \\ St. Thomas University School of Law, USA \\ WByrnes@stu.edu
}

This is a refereed article published on: 7 November 2001

Citation: Byrnes W H, 'A Review of the Development of an Internet Delivered LL.M Program in the United States', 2001 (3) The Journal of Information, Law and Technology (JILT). 〈https://warwick.ac.uk/fac/soc/law/elj/jilt/2001_3/byrnes> 


\begin{abstract}
This article reviews the development of the first Internet delivered LL.M program (i.e. LL.M. of International Tax and Offshore Financial Centers, the 'Program') in the United States.
\end{abstract}

The paper comprises four sections: In Part 1 the economics reasons for, and logistics considerations of, the Internet delivered Program are addressed. Part 2 reviews the pedagogical approach to legal education employed in the United States, criticisms thereof, and finally examines an emerging pedagogical trend in the United Kingdom. Part 3 reviews the teaching tools employed in the Program International Tax and Offshore Financial Centers, and Part 4 reviews the practical aspects of developing the Program, obtaining ABA acquiescence, and reviews the Internet delivered law courses that came before it. Finally, the article concludes with some personal observations.

Keywords: LL.M Program, LL.M. of International Tax and Offshore Financial Centers, Legal Education in the US, Legal Education in the UK, Internet Delivered Law Courses, C\&IT in Legal Education, CAL, CBL, Socratic Teaching Method, Alternatives to Socratic Teaching.

\title{
1. Introduction
}

This article reviews the development of the first Internet delivered LL.M. program (i.e. LL.M. of International Tax and Offshore Financial Centers, the 'Program') in the United States. In Part 1 the economics reasons for, and logistics considerations of, the Internet delivered Program are addressed. Part 2 reviews the pedagogical approach to legal education employed in the United States, criticisms thereof, and finally examines an emerging pedagogical trend in the United Kingdom. In particular, this part concludes that the grounding of a LL.M (Masters) level legal education program exclusively using the Socratic method (case study) roots of traditional Juris Doctorate (graduate) legal education may neither meet the goals, nor produce the skills sought by this Program. By example, some legal education writers have negatively critiqued the primary use of the Socratic method in even graduate legal education's pedagogy ${ }^{1}$. The scope of the negative critiques are presented from the perspective of economic efficiency over educational quality ${ }^{2}$, as well as the perspective of professional development ${ }^{3}$, and also

\footnotetext{
${ }^{1}$ American Heritage Dictionary, 2000: Pedagogy: 1. The art or profession of teaching. 2. Preparatory training or instruction.

'We recognize that economies of scale make Socratic and lecture models attractive, especially in large undergraduate and professional schools that cannot afford the teacher student ratios graduate departments typically enjoy' (Davis and Steinglass, 1997). Professor Davis (NYU School of Law) and Elizabeth Steinglass (Research Fellow at NYU School of Law and a doctoral student at the Harvard Graduate School of Education) participate in Workways, 'a multi-disciplinary collaboration designed to identify, analyze and develop the full range of intellectual capacities necessary to achieve excellence and social responsibility in the practice of law'. Davis and Steinglass cite Anthony G. Amsterdam, Jerome Bruner, David Richards, and Nancy Morawetz as the intellectual force behind the Lawyering Theory Colloquium of the New York University School of Law, thus I intend to follow up this Colloquium in my further research, see also, Hawkins-Leon, 1998. Hawkins-Leon states: ' $\ldots$...critics of the method fear that it is more costly than the Socratic method because it is best utilized in classes of forty students or less', see also, Thiemann, 1998, recommending smaller class sizes.

${ }^{3}$ Davis and Stienglass, 1997, at 251, (citing MacCrate, 1992 and Cramton, 1979, on urging law schools to place additional emphasis on various skills important to being a professional lawyer, such as
} 
from the perspective of a feministic approach ${ }^{4}$. These critiques are followed by a review of suggested alternatives. This part ends with an examination of the emerging United Kingdom literature supporting a pedagogy based upon 'student-centered learning'. Part 3 reviews the teaching tools employed in the Program International Tax and Offshore Financial Centers. Part 4 reviews the practical aspects of developing the Program, obtaining $\mathrm{ABA}$ acquiescence, and it reviews the Internet delivered law courses that came before it. Finally, the article concludes with some personal observations.

\section{Part 1: Economics and Logistics as Consideration for Implementing the Program}

\subsection{The Internet Economy and Education}

Education has become a 'new economy' leader in both the global and US markets'. From its roots as a communication medium for collaborative scientific research, the use of the Internet has penetrated all academic fields. The administrations of United States' higher-education institutions' are grappling with the potential for delivery of educational information ('distributed learning') ${ }^{6}$ at a lower cost and to a geographically diverse market ${ }^{7}$. As an academic tool, the Internet provides an innovative and effective medium for electronic delivery of educational materials, lectures (passive and interactive) and communication. As an administrative tool, the Internet reduces the need for traditional capital expenditures, thus allowing re-distribution of capital resources to other University functions, such as library collections, research facilities, and faculty enlargement. Also, the Internet provides the potential for a geographical market expansion, thus revenue stream increase (or retention, given competition), across local transportation boundaries.

The proliferation of graduate-level education institutions and entrepreneurial companies entering the Internet based education market points to the trend and increasing popularity of distance learning courses ${ }^{8}$. The reasons for this are numerous and dynamic. Firstly, university demographics have changed: a substantial portion of contemporary graduate students work full time and are thus only able devote part of their time to studies. Graduate students no longer want to lose a year of work experience or employment advancement. Also, there is an increasing need for educated professional bodies in relatively sophisticated financial, technological, and service

teamwork and oral communication, and Frank, 1951 on criticizing traditional legal education for an excessive focus on case law and theory rather than on client interaction and the lower courts) argue that legal curricula should focus also on the humanities.

4 Thiemann, 1998, applying Guinier's methodology conducted in her three-year study of gender and the Socratic method at Pennsylvania University School of Law to New York University's School of Law and exploring complementary alternatives to the Socratic method, see also Hawkins-Leon, 1998, at 16.

5 The industry of education accounts for approximately 10 percent of the US GDP. In 2003, higher education is forecast to reach eleven billion dollars. See <http://company.blackboard.com/index.cgi> for information regarding online education market growth.

${ }^{6}$ For example, The Journal of Information, Law \& Technology (JILT) is solely delivered by Internet at $<$ http://www.law.warwick.ac.uk/jilt/>.

${ }^{7}$ See <http://imsproject.org/collaboration.html>.

${ }^{8}$ A multitude of MBA and other business programs are delivered using the Internet. Regarding law programs, the US has seen a rise in Internet delivery since 1998-Concord School of Law being the most mentioned example. Concord, accredited by the State of California, is an Internet, distance learning based law school. 
industries that correspondingly have a limited geographic potential student body (e.g. offshore financial service industry).

Furthermore, due to a reduction in student enrollments, institutions are forced to consider the bottom line for many 'niche' courses/programs. This has resulted in institutional 'pressure' on professors to either drop courses with relatively limited attraction or to alternatively handle increased workloads without increased compensation. Another motive is that Federal and State governments are decreasing taxpayer support and subsidies for State owned higher education institutions, requiring these institutions to enroll more students. Thus, these institutions must spread their decreasing subsidy resources over larger student bodies. Related to that issue is the fact that required tuition levels to deliver high quality education for private institutions that do not have large endowments are unsustainable in a competitive local and national educational market, especially where student loans do not cover the entire tuition and State schools maintain lower government subsidized fees. And finally, competition in the graduate education market is increasing as entrepreneurial companies and institutions are able to enter the market due to reduced barriers to entry such as lower initial capital expenditure and ability to compete across geographical boundaries.

Despite its lofty classical roots, ivory towers will not shield legal education, especially the smaller, geographically remote law schools from the above economic and technological considerations ${ }^{9}$.

\subsection{The Decision Process for the Internet Based Masters of Law Program}

Before making the decision to offer an Internet delivered Masters of Law program, integration of the Internet with legal education must be a matter of strategic thinking by the Faculty and Administration. A law school should consider several issues in its decision to pursue integration between legal education and the Internet. From a pedagogical perspective (addressed in Part 2 below), a law school's faculty may determine a need to provide a complementary methodology for its legal teaching methods. Collaterally, the law school may want to stay in the academic and technology forefront relative to competitor law schools. The law school may also want to maintain or increase the student body size beyond the law school's geographical boundary. Reasons for this cause may be financial in light of local competition or a decrease in the local student market. Alternatively, it may be pedagogical, i.e. - to increase student diversity, including the intake of foreign students. The law school may need to expand, for niche subjects, a class or program's size beyond the law school's geographical boundary for reasons of the course or program's financial viability or student diversity. The law school should also consider whether law school's mission may require providing legal education to geographical areas without law schools or to persons without access to local legal education, for example, economically disadvantaged persons.

\footnotetext{
9 'The monastic approach to learning for three years or more in the ivory tower was sustained by the geographical imperative of getting teachers and scholars together. In the age of the Internet, the positive aspects of physical commune do not disappear, but are reduced', (Paliwala, 1998).
} 
After deciding whether to pursue Internet delivered legal education, the institution must then address its position regarding the pedagogy of legal education via the Internet. The faculty discussion will likely produce heated debate between the monastic school traditionalists and the technological pioneers. Finally, the institution must address the issue of potential Internet integration while maintaining compliance with the (1) American Bar Association (ABA) accreditation standards, (2) its regional accrediting body such as the Southern Association of Colleges and Schools (SACS), and (3) if it has obtained a high level of academic standing, then with the American Association of Law Schools (AALS).

Regarding the institution's internal discussions, aspects that are likely to be considered by the faculty should include the development of learning strategies that integrate different educational technologies; the target size of the intended program's student body; effective utilization of available resources through collaboration with various departments of the university and law school where appropriate and proper in that the leveraging of law school resources may not negatively effect the resources available to the JD program; commitment to hiring additional staff, faculty, and graduate-student assistants where necessary; capital investment in the creation of the courses' materials to be offered in the program; and the provision of Internet delivered research materials for each student.

St Thomas, in support of its mission to achieve student diversity, wanted to outreach to a student body the law school's geographical boundary (i.e; from The Mission of the School of Law:

'[v]aluing difference, affirmatively welcoming to the law school community a richly diverse group and [c] reating and nurturing relationships ... with and among our international neighbors in the global community'.

The Program's student body is between one-third and one-half non-US based, some from developing economies, and almost all of the students live outside the Miami/Dade County area.

Also, St Thomas needs to stay in the academic and technology forefront relative to competitor law schools. St Thomas will face a direct competitive threat in two forms from the year starting 2002. First, Florida International University (FIU) School of Law, a new State owned law school located just miles from St Thomas, whose student market is similar to St Thomas, will intake its first class at a tuition level less than a quarter of that of St Thomas. Secondly, NOVA Southeastern School of Law, also located within fifteen miles from St Thomas, has already begun offering its first Internet delivered law program, and started marketing for its second Internet delivered program. Not only does St Thomas' LL.M. Program provide bottom line revenue support to the J.D. law program in light of the FIU competitive threat, but it also keeps St Thomas competitive with NOVA regarding the technological forefront.

\subsection{Delivery System and Support}

As of 2001, the choice among internet-delivered educational systems is vast, with several companies marketing their educational software programs. From the perspective of compliance with the standards established by the ABA and AALS, the decision 
process must be driven by the requirement to replicate and maintain the quality of interaction occurring in the classroom in addition to the residential law school environment. From an operational perspective, the technology must be as user-friendly and self-explanatory as possible in meeting the above objective while allowing for seamless multimedia delivery (i.e; audio and/or video streaming), as well as provide access and download of chat room messaging within seven seconds while utilizing a $56 \mathrm{~K}$ modem connection. A slow download and chat room interaction technology may be compared to a professor halting a lecture, turning his back, and remaining silent for a period of time. Clumsy or lumbering technology distracts from interactivity.

The St Thomas University School of Law (Law School) undertook a discussion about its core competencies. The conclusion: the law school's core competencies are teaching and research, not technology. Thus, the law school, to leverage the capitalized knowhow of technology experts, to guarantee smooth delivery to its students, and to limit its upfront expenditure, outsourced its Office of Information Technology to Collegis; a private firm. Yet, in order to preserve the capacity for an exit strategy from its outsource partner and to preserve the capability to pursue a skills transfer strategy in the future, the Law School established its licensed delivery system, Blackboard, on its own server equipment. This decision required upfront capital expenditure for hardware, software, and the upgrade of telecommunications cabling, while further requiring continued lease costs of bandwidth from the local telecommunications provider.

\subsection{Development of the Program}

The international tax planning and offshore financial centers industry has been undergoing drastic changes pursuant to anti tax-competition and global harmonization policies pursued by the OECD, G8, EU, and US. The industry by its nature deals with cross-border transactions and offshore (non-US) jurisdictions ${ }^{10}$. The degree for international tax planning naturally attracts professionals residing around the globe, in particular, those individuals that have previous experience with multinational business. These professionals' profiles are typically 30 - 40 year old, cross-disciplined attorneys or accountants in the tax departments of audit firms, law firms, corporations, financial institutions, or trust and secretarial service providers ${ }^{11}$.

These professionals have stated that one-year or longer physical absence from their employment would critically damage their careers because they would lose by example client relationships, intra-firm networking, annual salary and bonus along with other negative consequences. Also, the expense of a one-year family move or the burden of a year of separation from their family presents an insurmountable barrier. Thus, traditionally, residence based programs in international taxation have drawn very few high level, older practicing professionals and thus must rely upon the less experienced

\footnotetext{
${ }^{10}$ The term 'International Taxation' in the context of St. Thomas's Law School program (hereinafter the 'Program') does not refer solely to the examination of outbound and inbound transactions as the term is commonly used in traditional US tax degrees. Rather, the term refers to a non-national specific comparative study of the meshing of tax systems in order to provide a global perspective for multinational enterprise planning. For example, the program examines the causes, results, planning, and occurrence of the flow of the 50 percent of the world's monetary funds that pass through and are held in offshore jurisdictions such as Switzerland, Bermuda, Cayman Islands, Hong Kong, and Luxembourg.

${ }^{11}$ For example, companies and firms include: Merrill Lynch, PricewaterhouseCoopers, Deloitte \& Touche and Credit Suisse.
} 
younger student. Problematically, an executive level Masters program like that of the Law School does not match with the profile of younger students because of their lack of industry experience. Thus, a full time residency requirement places steep barriers between the management level decision makers of the firms and an executive level academic education.

Other paths of delivery were explored and tested for the Program. One week, sevenhours per day teaching seminars were employed. But this format does not allow the gradual introduction of ideas and the required time to research each step of the formation of ideas. The gradual development of case studies is stunted. Finally, the ancillary cost of a program becomes prohibitive because of travel and accommodation expenses incurred in the required monthly trips of the students and of the faculty specialists ${ }^{12}$. The end result is that an unfortunate divide is imposed between the decision makers in the offshore financial services industry and accredited, University education.

\subsubsection{Researching the Market}

The Program's goal is to enhance the careers of professionals in the international tax planning and offshore financial centers industry and improve the industry through Executive level accredited education. The program and its curriculum were developed, not only in consultation with representatives from major firms in the industry, but also with input from small entrepreneurial firms. Up to the date of inception of this Program, no master's level program existed for this area of study.

The consultations brought to light that employers required trained manager level associates in their international tax departments and would assist staff with tuition reimbursement. Also, employers wanted their advisors from different offices in several jurisdictions to participate in an executive level training program specific to this field. Finally, employers were not interested in releasing their professionals for a year or more of active employment in order to undertake a program of study.

\subsubsection{Intended Student Body}

An important feature in the Internet based Masters level education equation is the audience (i.e; the intended student body). An Internet based program will not achieve the stated learning objectives for everyone that applies. In developing the online Masters program, the program faculty pondered the questions posed by John Dale (1998). For whom is the program intended? What are the audience's expectations and capabilities, and what sort of technology access will they have? And lastly, where are they located?

Disciplined adult learners with contextual experience in the field will generally respond better to the higher level of education than contextually inexperienced learners. On the other hand, younger learners (more recent graduates) that have contextual Internet

\footnotetext{
${ }^{12}$ For example, the Program encourages a 'global' class for cross regional and national interaction. Thus, the Program regularly accepts students from Russia, China, Japan, Hong Kong, Singapore, South Africa, and numerous small island financial centers, among other locations at least a ten-hour flight time from the US. The air travel alone would cost more than $\$ 2,000$ per trip to the University to attend lectures. As any program of substance should require a minimum of ten lectured courses for completion, the air travel expense at over $\$ 20,000$ would cost more than tuition.
} 
experience respond better to the technology, whereas older learners experience technology shock.

The current Masters program has been marketed to attorneys, accountants, and trust professionals in four regions: the Americas (North America and Caribbean); Europe; Asia; and South Africa. As postgraduate students (having matriculated), they are expected to have a rudimentary knowledge of critical research, and problem-solving argumentation. They must also have an awareness of the basic concepts of domestic tax law of a jurisdiction.

The Admittance Committee, comprised of Professor William Byrnes with support from the Dean, focuses on the curriculum vitae and written statement of each prospective candidate to determine the level of competency in the field. Also, Professor William Byrnes speaks with each candidate through a telephone interview to discuss the program's curriculum, technology requirements, necessary time commitment, and discipline factor. He asks the candidate about the past use of Internet. Finally, the he informs the candidate that the candidate should receive firm permission to forgo billable time in favor of study. Many students are sponsored by the employer through a 'continuing years of employment' based loan forgiveness program and thus already have the employer's commitment.

\section{Part 2: The Pedagogy for the Internet Delivered Program}

Because the Program had to be approved by a majority vote of the law school's faculty, a discussion will ensued between the monastic school traditionalists and the technological pioneers. This discussion in focused on the use of the Socratic Method in the Program's pedagogy. Consequently, Part 2 reviews the pedagogical approach of the Socratic Method, criticisms thereof, and finally examines an emerging pedagogical trend of 'student-centered learning' in the United Kingdom. The Program's pedagogy follows the United Kingdom approach in combination with the suggested US alternatives to the Socratic Method.

\subsection{Review of Socratic Case Method Employed in US Legal Education}

Professor Theodore Dwight, of Columbia Law School is historically credited with the introduction of the Socratic method into US legal education during the $1850 \mathrm{~s}^{13}$.

However, the use of the Socratic method in combination with the Case method dates its introduction to 1870 by Christopher Langdell, then Dean of Harvard Law School ${ }^{14}$.

\footnotetext{
${ }^{13}$ Johnson, 2000. Professor Dwight employed the Socratic method for his assessment of the students' understanding of his lectures at Columbia from the late 1850's until 1881 when he was removed to make way for a curriculum change to the Socratic-Case method, see also Sheppard, 1997 for an interesting review of the history of US legal education pedagogy.

${ }^{14}$ See Davis and Steinglass, 1997, at 261, see also Hawkins-Leon, 1998, at 4. For purposes of this article, references to the Socratic method approach include the correlative use of the Case Method, as applied by Langdell. The terms are generally used synonymously in legal education writing because the two methods are used hand-in-hand in practice. However, employing the Socratic method approach of questioning is not synonymous to using the Case Method. For example, a professor could employ a roleplaying approach in combination with the use of cases.
} 
Dean Langdell's stated goal for legal education was to have his students develop a mastery of legal principles or doctrines and that those doctrines would be applied:

'with constant facility and certainty to the ever-tangled skein of human affairs...' and said further '... [this] is what constitutes a true lawyer; and hence to acquire that mastery should be the business of every earnest student of law' (Davis and Steinglass, 1997, at 263).

The pedagogy of the Socratic method accredited to Langdell is to force students to develop analytical skills through their focused analysis of cases. In the analysis process of a case, the professor requires that a student be able to identify the significant rules and extrapolate the court's analysis, be able to articulate understanding of the rules of law and derive the judges' policy considerations (Hawkins-Leon, 1998, at 5).

The Socratic method process requires professor-students (' $p$-s') interaction regarding the analysis of cases throughout the course. The role of Socratic mediation of cases is a subtle role, occurring in the linguistic interplay during the series of the contact lectures comprising a course ${ }^{15}$. After three years of continuous Socratic method case analysis, the students should emerge with new analytic processes, claimed respectively as their own.

Professor Paul Bateman summarizes the goals of the Socratic method as being to develop attitudes of inquiry that involve an ability to recognize the existence of problems and an acceptance of the general need for evidence in support of what is asserted to be true, enable students to acquire knowledge of the nature of valid inferences, abstractions and generalizations, in which the weight or accuracy of different kinds of evidence, are logically determined and to develop student's skills in employing and applying the above attitude and knowledge (Bateman, 1997).

Professor Hawkins-Leon states that the following five points are the recognized result of the Socratic method:

students develop analytical skills; students are forced to think on their feet ${ }^{16}$, the method encourages intellectual rigor; students learn about the legal process; and students learn about the lawyer's role or function (Hawkins-Leon, 1998, at 5).

Summarizing this pedagogy of legal education, it is not merely an education of the law but rather it is a (re)-structuring of the thought process. Whereas any literate individual is able to memorize the law, a law student should learn (1) how to derive and analyze the law and (2) how to apply legal analysis in the context of different fact scenarios. The Socratic method remains the primary technique for legal education (Kerper, 1998).

\footnotetext{
${ }^{15}$ Courses in the US are generally either two or three credit hours, referring to the number of class contact hours per week (a class hour is only 50 minutes). A course generally runs between twelve and fifteen weeks. Thus, a three-hour credit course may have 45 class lectures.

${ }^{16}$ Oberst, 1996, quoting from Johnson, 2000, at 110: 'Whatever success I have in developing my students' analytical skills mainly results from my holding them accountable in class'.
} 


\subsection{Review of Criticisms of the Socratic Method}

Professors Davis' and Steinglass' theme is that the Socratic method alone is unable to create these necessary skills required by modern legal education (see section 4 below for their stated goals). They further state that the Socratic method hinders professorstudent interaction, correspondingly and independently hindering the creative thinking process (Davis and Steinglass, 1997, at 270-271, 274). Their research shows that the method of successive questioning results in the student becoming passive in the learning process rather than taking responsibility for $\mathrm{it}^{17}$. Also, the Socratic method requires a power differential (e.g. master-servant relationship) for the dialogue to be accepted by the student (Davis and Steinglass, 1997, at 270). In step with this criticism, Sarah Thiemann comments that the application of the Socratic method leads to public humiliation, that being against sound education principles (Thiemann, 1998, at 21).

Along a different line of criticism, in the presentation of her two year research Professor Cynthia Hawkins-Leon states that the Socratic method has been criticized on two grounds: first, it replaces students' learning the legal thought process through their own rigorous mental analysis with their learning by example of others, and second, it draws attention to case outcomes rather than to the process of achieving the outcome (Hawkins-Leon, 1998, at 6-7). She draws attention to the critiques by the AALS committee on teaching and examination methods (1942) and Professor David Cavers ${ }^{18}$. The AALS Committee found that the Socratic method in practice led to students being stymied in their analysis of cases because the cases were considered authoritative solutions. The Report negatively critiqued that the students were not focusing on analyzing and resolving fact scenarios that would present themselves in the future, but rather only focused on examples of what has been done in the past (Hawkins-Leon, 1998, at 6, see also, Kerper 1998, at 356). Professor Cavers provided two further critiques. The first being the Socratic method does not provide a 'well-defined or elaborated technique for case review' and second, the students' active relation of law to fact is replaced by a passive acceptance of the cases' relation (Hawkins-Leon, 1998, at $6)$.

Professor Kerper states that the Socratic method develops skills that are 'at best rudimentary; the much touted 'legal analysis' of the case method is little more than a narrow articulation of rather obvious adversarial positions, accompanied by the selective matching of factual data with so-called legal elements to justify the positions advanced' (Kerper, 1998, at 352). Professor Kerper further states that the Socratic method hinders the students from creating problem resolution skills (Id). Professor Diana Donahoe believes, following the critique of Professor Hawkins-Leon, that the Socratic case method teaches students to 'categorically label' rules pursuant to a West 'box'. Her conclusion is in step with Professor Kerper, that the students will not become creative problem solvers ${ }^{19}$.

\subsection{Review of Goals of US Legal Education}

Professor Davis and Steinglass' stated the goal for legal education is:

\footnotetext{
${ }^{17}$ Id; at 271; see also Thiemann, 1998, at 24, offering further support in her study at NYU Law School.

${ }^{18} \mathrm{Id}$; referring to Cavers, 1943.

${ }^{19}$ Donahoe, 2000, at para 62 (Professor Donahoe is an Associate Professor at Georgetown University Law Center.).
} 
'...to provide contexts in which students can learn fundamental legal concepts, develop intellectual versatility, learn to use the range of their intellectual capacities across the range of lawyering tasks, and to develop a critical consciousness about their professional role'.

Having undertaken a two-year research project, they present the conclusion that there are several skills that should be the goal for legal education, these are: logicalmathematical, interpersonal, intra-personal, narrative, categorizing and strategic intelligences.

Thiemann's theme is to promote the inclusion of feminist pedagogy in legal education. She states that feminist pedagogy is comprised of the following five elements:

'1) a collaboration of teaching and learning to narrow the gap between professors and students, 2) a cooperative communication style to decrease adversariness, 3) a holistic approach to learning which incorporates many styles and disciplines, 4) strategies for theory building that encourage students to introduce theories in opposition to, or in support of, existing ones, and 5) action projects to incorporate clinics or projects with classroom learning' (Thiemann, 1998, at 25).

Thiemann's goal of good teaching is for the professor to create the 'less-confrontational, more-inclusive' comfortable classroom (Id. at 21,25). She deems attributes of good teaching are to create a good rapport while maintaining order as opposed to a confrontational method, allowing students to develop effective language skills through increased participation, to create a sense of community within the classroom by recognizing, and holding in esteem each individual and to minimize anxiety levels because low classroom stress levels lead to quicker, more effectively learning (Id. at 2224).

Professor Hawkins-Leon's goal for legal education is to bridge the gap between the Socratic legal education and the practice of law (Hawkins-Leon, 1998, at 3). She reasons that it is well recognized that the role of the lawyer in present society has evolved from merely that of an advocate for a client to that of a planner and advisor (Id; at 15). The required attorney's skills that must result from legal education today are many and include the capacity to think through and unravel fact patterns, the ability not to accept the opinions of others without review and reflection, the talent to make a searching analysis of a group of facts and disclose the legal problem involved, to have enough imagination to discover possible solutions and lastly, the patience to investigate the validity and practicality of the various solutions and the courage to form and then act upon their own judgment.

Professors Kerper and Donahoe's goal for legal education is similar to Professor Hawkins-Leon: i.e; bridging the gap (see Kerper, 1998, at 353, see also Donahoe, 2000, at para. 64). In line with Professor Hawkins-Leon's assessment of the role of the attorney, Professor Kerper states the student should learn relationship-building skills in order to avoid conflict (see Id. at 354). The student should also learn collaborative skills, such as integrative bargaining, to help mitigate the effects of conflict, and correspondingly, Professor Kerper states that problems must be viewed as 
'multidimensional, often requiring non legal or multidisciplinary solutions' (Id.). Professor Donahoe focuses on the goal of teaching 'out of the box' problem solving skills that may be employed to avoid conflict.

\subsection{Alternative Methods Suggested by US Academics to Accomplish Goals}

Professors Davis and Steinglass suggest that law professors employ complementary teaching methods to the Socratic method to ensure that every student is actively participating and thinking. Some of their suggested methods include such things as requesting students to write their thoughts out in class and bring written responses that will be shared in pairs or small groups in addition to organizing classes to including small group discussions in which students can speak more comfortably and develop ideas that can then be discussed in the larger group, to analyze cases through role playing, the assignment of problems and even creating on-line discussions that will assist students who are wary of speaking in public or of speaking extemporaneously and will address a broader range of subject matter than can be addressed in time-limited classes (Davis and Steinglass, 1997, at 275).

Thiemann suggests a substantially similar list of suggestions to Professors Davis and Steinglass above, adding to it: (1) a review of actual case files, (2) narrative story telling, and (3) take home/midterm/paper options and practice exams. She goes further to suggest that for the Socratic method to be useful, it must be reformed in three of its fundamental attributes. First, students should be alerted to the class date of the intended questioning, allowing the student to prepare consistent as with preparing for a day in court (Thiemann, 1998, at 28). Secondly, the questioning should:

'seek to engage not only rational analysis, but also emotional responses' (Id, quoting Williams, 1993).

Finally, the professor should employ role-playing for case analysis. ${ }^{20}$

Professor Hawkins-Leon states that a combination of the problem method and the Socratic method should be employed in core courses to achieve her stated goals.

There are many positive aspects to this combination approach as presented by Professor Hawkins-Leon ${ }^{21}$.

- Closely approximates the lawyer's approach to the law. Students must find their own answers to questions rather than merely read and memorize someone else's answer(s).

- Provides training in planning and advising and teaches the skill of organization or issue-management (the organization of a cumbersome set of facts and issues).

\footnotetext{
${ }^{20}$ Thiemann, 1998, at 28, quoting her discussion with Professor Kate Silbaugh, Boston University School of Law.

${ }^{21}$ Hawkins-Leon, 1998, at 9 (These aspects are verbatim and reference the findings presented in the Association of American Law Schools 1966 Proceedings Pt. 1, Report of the Committee on Teaching Methods, The Problem Method Survey and Appraisal.).
} 
- Broadens the range of matters open to consideration by students because they are required to prepare answers to an established problem set.

- Increases the effectiveness of instruction in comparison to the Socratic method.

- Stimulates student interest in legal study, as students are likely to be more prepared for class participation since they have received the problem in advance and can therefore anticipate class discussion.

- Allows the integration of relevant, non-legal source materials (such as economics and psychology), which may lead to a more enriched curriculum and allow students a greater breadth of inquiry. The disadvantage here is that law students often have a tendency to ignore the relevance of non-legal materials.

- Allows and encourages testing of students' understanding of the assigned readings. The AALS 1942 Report stated that 'frequency of examination is...urged as a method for maximizing the efficiency of a teaching program.' In application, the problem method allows for frequent examination of students' performance -- a professor could require answers to various problems to be submitted in writing for review, written comment and grading.

However, the negative aspects are also expressed as presented by Professor HawkinsLeon: (Id at 10).

- The professor must devote more time to course preparation in order to draft problems and their answers. The creation of textbooks utilizing the problem method of instruction is of immeasurable assistance. Course books for some subjects already exist and some problem books have been created for use with a standard textbook. Students are also required to be more consistent in their class preparation and may have to spend more time preparing for class.

- The problem method is more costly than the Socratic method because its usage is most effective in smaller classes. Research has shown that ideally no more than 40 students should be enrolled in a course taught by the problem method. This factor causes the problem method to be more costly than the Socratic method, which is ideal for large class sizes.

- Professors are not as much at liberty to teach via lecture when the problem method is utilized.

- Due to the in-depth discussion of individual problems, critics fear that less course material is covered when the problem method is utilized. Contrary to this concern the results of the 1966 AALS survey showed that professors utilizing the problem method covered more course material. 
Professor Kerper's suggestion is to supplement the application of the IRAC method to case analysis with problem solving methods, including what she acronyms 'SOLVE' 22 . Her suggested problem solving method acronym involves: a Statement of the problem, Observing and organizing the problem through the identification of initial conditions, goals, resources and constraints, Learning by questioning all parts of the problem, to $V$ isualize Possible Solutions and to Employ the Solution and Monitor Results ${ }^{23}$.

Professor Donahoe suggests that students play out case studies, working both alone and in groups (Donahue 2000, at para. 64). The case studies may be in the form employed in most law exams: factual hypothetical, problem sets, or actual facts from an appellate case. The class time should be used to explore the various methods of researching and resolving the case study. When using an appellate case, the decision should serve as a comparative model answer after the classroom exploration.

\subsection{The Emerging United Kingdom Pedagogical Approach to Online Legal Study}

In his most recent article, Professor Abdul Paliwala ${ }^{24}$ asserts that education, legal education or information technology in legal education are experiencing a convergence of their respective shifts in pedagogical approaches: 'from teaching to learning, and particularly towards 'student centered' and 'independent' learning' (Paliwala, 2001, see also Paliwala, 1999). Professor Paliwala's primary pedagogical theme is that:

'cognitive psychology has changed from seeing the learner as a passive recipient of information to 'a self-determining agent who actively selects information from the perceived environment, and who constructs new knowledge in the light of what that individual already knows", 25

Langdell introduced the Socratic method also to create a student-centered, active learning approach.(Johnson, 2000, at 88). However, referring back to the criticisms enunciated about the Socratic method, during a traditional class period few students have the opportunity to participate in directly focused professor-student interaction. Rather, most of the students are presented with a passive learning opportunity of observing the focused professor-student interaction of potentially up to three class members during any single class period. Over the several weeks of a course, presumably each student will experience one or two substantial, focused professor student ('p2s') interactions ${ }^{26}$. Time is the primary factor of a lack of attention to each student in each class period- a professor, during any fifty-minute class, is only able to call on so many students and still achieve an effective, focused Socratic dialogue.

\footnotetext{
${ }^{22}$ Kerper, 1998, at 367, see also Moskovitz, 1992. Professor Moskovitz, a professor at Golden Gate University School of Law, argues for totally replacing, in all courses, the case method and correspondingly the IRAC method with the Problem Solving Method.

${ }^{23}$ Kerper, 1998, at 367-370. Kerper's Problem Solving method is presented by using the acronym: SOLVE, but she lists other potential problem solving methodologies.

${ }^{24}$ School of Law, University of Warwick.

${ }^{25}$ Paliwala, 1999, referring to Le Brun and Johnstone, 1994, p.56 and their citation of Biggs , 1989, p/ 8.

${ }^{26}$ See Terry, 2001, quoting from his analysis of the future of legal education: 'It is also because we overestimate the law school time actually devoted to interaction (as opposed to, for example, independent study) and the quality of the interaction that actually takes place in our classrooms'.
} 
Thus, much of a student's learning process in the classroom occurs while passively observing others' direct interaction experience in the classroom as opposed to actively interacting with the professor. Further, of the total amount of time of a student's learning experience, a majority of it occurs outside the classroom interacting with resources ${ }^{27}$. Still further, after the student completes a degree, continued learning occurs almost solely through interacting with resources and in the context of practice ${ }^{28}$. Consequently, we can conclude that instilling student methodology and discipline for the interaction process with resources must be a key component of any pedagogy of learning ${ }^{29}$.

Thus, one role of the legal educator is a professor who teaches effective independent learning and resource based learning (Paliwala, 1998). Quoting Professor Abdul Paliwala:

'The role of the educator is to mediate between the resource and the student ${ }^{30}$

\section{Quoting Professor Diana Donahoe:}

'Starting with content, does it make sense in the new paradigm to begin teaching with a rule from an appellate court case and teach students how to categorically label that rule... before they apply the facts? These students are not categorical

\footnotetext{
${ }^{27}$ As an accepted rule of thumb, a US law student should spend three hours of reading and preparing for an hour of contact lecture time. Thus, 25 percent of learning time occurs in the classroom. However, one could give a higher weight to the portion of the time spent in the classroom.

${ }^{28}$ Paliwala, 1999 addresses the approaches of situated and contextualist learning. In the framework of European legal education, generally an apprenticeship type relationship must be completed before a degreed candidate may practice without supervision (mentioned by Mayer, 1999) - a practice I think the State Bar Associations should consider.

${ }^{29}$ One of the proposed positive critiques of the Socratic method is that it forces students to read and prepare assigned cases. However, Theimann (1998) states in her findings at NYU: that it encourages students to miss class, thus the students miss the opportunity for interaction regarding the prepared cases. Secondly, she states that the students do not consider the Socratic method a practical approach to the practice of law, see Theimann, 1998, at 27. In summarizing Hawkins-Leon's critique, the Socratic method applied in the classroom encourages the student to remain within the case analysis, rather than perform independent, ancillary analysis.

${ }^{30}$ See Paliwala, 1998, 1999. Quite often I am asked at conferences: 'Will online law schools reduce the role of the law professor to that of a teacher assistant?' This question has been put forward in articles and discussions in the CALI seminars. My response is: 'In light of the critiques of the Socratic method in relation to the student numbers in most first year law classes, in what way do you think that on-line delivery of materials and discussions changes the fundamentals of the established learning process in the US of teaching from casebooks and teacher notes prepared by other authors?' Rather than demote the role of the professor, the online possibilities enhance their role. If we consider one of the roles of the legal educator to be that of an intermediary, then there is a strong argument that the importance of the role of the legal educator will increase in the online learning process. The Internet multiplies the availability of resources and methods by which to interact with those resource possibilities. Each professor must, in essence, research and author his or her own methodology for resource interaction. The job of the legal educator to intelligently and efficiently package the available information becomes more difficult and time consuming. Online classroom presentations require more focus on the academic and research role of the professor, criteria adopted by most law faculties in assessing potential tenure. As an interesting side note, positions in the job market for niche subject matter are increasing as a result of C\&IT. See generally Sheppard, 1999). Finally, it is my opinion that the methodology of assignments and feedback required in interactive online courses is not suitable for large class sizes, but rather smaller ones of no more than 40 students, because of the individualized attention required for each student.
} 
labelers - they are discovery-based information gatherers' (Donahoe 2000, at para. 62, 73).

Note that the role of mediation is more substantial than at first glance. When considered, several questions are raised. Of all resources made available through new technology, which ones should be studied? How may a student identify which resources should be consulted and studied? How may the student determine the method of study best fit for a particular resource? What if there are no directly applicable resources available, how does the mediator teach a lateral thinking approach to gathering resources?

Secondly, the professor, as an academic seeking to further the knowledge base in his chosen specialty(ies), should herself be a resource creator ${ }^{31}$. As a resource creator, the professor creates a perspective that should be studied in the context of resources available and critiqued in relation to those resources (Donahoe 2000, at para. 73).

Thirdly, for many specialist legal studies programs, such as a post-graduate Masters program, the contextualist method is required for the learning process ${ }^{32}$. Thus, the professor must mediate between contextual situations (e.g. case studies), the resources, and the student (Paliwala, 1999).

\subsection{Instructionists, Contructionist, and Contextualist Approaches Employed by United Kingdom Legal Educators}

Three prevailing teaching approaches that provide an effective teaching/learning environment are the Instructionist approach, the Contructionist approach, and the Contextualist approach ${ }^{33}$.

The precept of the Instructionist is that the ideas to be communicated exist in an environment outside of the student's experience (Paliwala, 1999). In order to efficiently transfer understanding of the ideas, a complete structure must be modeled for the student. The Instructionist approach may be necessary to initialize the learning process wherein students may absorb predetermined presentations of objective knowledge. This approach tends to efficiently facilitate the surface learning stage, providing foundation for an accompanying Constructionist approach.

The Constructionist approach is based on the recognition that students have different cognitive methods of processing information (Id). For cognitive learning to occur, students require integration of information into their own respective mental models. Students' mental models are developed within their social context. This context is represented macroscopically by the cultural background and microscopically by interaction between teacher and students, and among other students. Thus, the

\footnotetext{
${ }^{31}$ An academic has a greater possibility of publication through the relatively inexpensive process of Internet dissemination of material. The important factor in academic publication is peer review and critique, not paper based dissemination. Furthermore, an academic has a greater opportunity to reach a geographically diverse audience for niche subject material through Internet dissemination of materials. ${ }^{32}$ Employers and potential employers expect a reasonable experience and skill level to be obtained from an employee undertaking a post-graduate (Masters) law program.

${ }^{33}$ Widdison and Schulte, 1998, discussing the approaches citing Jonassen and Reeves ,1996, 693 - 719; see also Paliwala, 1999, 2001. I present brief descriptions in the following paragraphs herein for purposes of our discussion.
} 
Constructionist encourages the students to develop their own unique interpretations of reality in a self-regulated process in which the students autonomously create new knowledge structures and link them with the other available ones.

Knowledge is bound to multiple contexts and must be regarded from multiple perspectives. The students' interpretations must be developed from a professor's careful planning of external resources that lead the students' through their respective reflective thinking in order to assemble their own personal knowledge bases (Id, referring to Jonassen and Reeves 1996 and Weaver et al 1996).

Nistor and Ertl have expressed various basic constructionist advantages for Internetbased learning environments. They state learners' active participation consists mainly of being involved in message exchanges, which serve as a vehicle for their results of problem solving, as well as for related comments from co-learners or from a tutor. Learners can also test and extend their available knowledge structures by exploring cases or reviewing learning materials; during the learning activities, learners' knowledge construction is assisted by feedback from peers and/or tutor. In addition, net-based, and especially asynchronous communication, support a wide range of freedom regarding organization and coordination of learning activities. However, instructional support is needed because the learners mostly lack self-regulation skills. Participating in the task-oriented discussions leads the learners to look at the learning contents from multiple perspectives; furthermore, the authenticity of the learning environment has an important potential: net-based learning brings the opportunity of an easy access to authentic and up-to-date learning materials. Lastly, cooperative learning is widely possible, provided that one keeps in mind the limitations of the communication medium. In virtual communities of practice, experts can be involved in learning activities in which they, otherwise, could not have taken part for organizational reasons. Tele-tutoring can also be applied. When these features are utilized, the net-based learning environment can effect the desired Constructionist 'deep learning' outcomes.

The Contextualist approach includes three aspects of learning: situation in the environment (subject matter) of the study ('situational' aspect), active interaction with the context of the environment ('active' aspect), and reflection upon the contextual interaction ('reflective' aspect) $)^{34}$.

'Because academics are concerned with how their subject is known as well as what is known, teaching must not simply impart de-contextualised knowledge, but must emulate the success of everyday learning by contextualising, situating knowledge in a real-world of activity. However, academic knowledge has a second-order character, as it concerns descriptions of the world. So whereas natural environments afford learning of precepts through a situated cognition, teaching must create artificial environments which afford learning of precepts i.e. descriptions of the world...academic teaching must address both the direct experience of the world, and the reflection on that experience that will produce the intended way of representing it' (Paliwala, 1999, quoting Laurillard,1993, p.28).

\footnotetext{
${ }^{34}$ Paliwala, 1999, 2001. The contextual learning approach is best exemplified by the use of law school clinics in place of European style apprenticeships; see also Thiemann, 1998, at 20. Thiemann refers to the element of contextual approach in legal pedagogy. Note that her presented definition of the context of legal study is the preparation of the adversarial role played by the attorney, identifying the contextual approach with the Socratic method.
} 


\subsection{The Goal of UK Legal Education}

The didactic goal of UK legal education is to lead students to the imaginative acquisition of knowledge and to encourage them to think independently, critically, freely and clearly (From Whitehead, 1967, see also Entwistle, 1979 and Twining, 1994). This approach produces students with a trained mind, capable of effective evaluation, research, analysis, synthesis, flexibility and critical thought.

Imparting a basic knowledge of law is a component of a program's legal education. Also, a program's educators must teach a comprehension of the law's relationship to the social-economic environment in which it operates. A program's courses should test the students' ability to ascertain facts from scenarios and the students' ability to apply abstract concepts to the ascertained facts ${ }^{35}$. Another component of a program's legal education concerns teaching methods of research for the program's subject matter. In addition, a graduate level Masters program's legal education must render a student vocationally competent (i.e; a student must master the skills necessary to practice in the niche of tax law in an LLM, Taxation); an ability that not only necessitates critical thinking skills, but necessitates Contextualist skills.

If a legal education is to enable such critical thought, it must facilitate depth beyond simple surface learning (Id). Surface learning may enable a student to absorb large quantities of detailed information and reproduce it. But legal educators agree that this is not the purpose of legal education. Rote memory deteriorates with time. If teaching fails to take a student beyond the superficial stage of learning, then the student fails to comprehend the underlying information. A student who has experienced deep learning obtains the ability to conceptualize and to understand what is signified: the spirit, not simply the letter, of the law. Such learning becomes a foundation for application of new knowledge.

In order to facilitate this level of learning in relation to the time limitations of the contact lecture classroom discussed above, the teaching methods applied must go beyond the classroom. Computer mediated teaching, hypertext in particular, has great potential to assist in providing such a learning environment (Paliwala, 1999, see also Jones and Scully, 1996, and Shiels). Because of its capacity to provide access to large amounts of information, and to format the body of that information, computer mediation lends itself to the ideology of holistic legal study. If teamed with an effective teaching approach, computer mediation could become the medium that creates the environment ideal for the highly varied, complex and non-linear field of legal studies ${ }^{36}$.

\footnotetext{
35 The Ormrod Committee, discussed by Jones and Scully, 1996.

${ }^{36}$ Refer to the joint project of Professor John Blackie, University of Strathclyde, and Dr. Paul Maharg, Glasgow Caledonian University, concerning teaching Torts through disputing (mooting) using the Internet in Blackie 1998.
} 


\section{Part 3 - Methods Utilized In the St. Thomas Program and Their Benefits}

\subsection{Teaching and Learning Methods Employed in the Program}

The Program's St Thomas faculty consists of the Executive Director, Professor William Byrnes, who is in his fourth year of experience in Internet delivered training at ABA accredited law schools. Professor Byrnes is assisted by St Thomas Professor Gordon Russell (Librarian) and St Thomas Professor Siegfried Wiessner (International Law). The adjunct faculty consists of Professors from primarily European Universities' law faculties' tax programs; a Commonwealth Revenue official; a former IRS Revenue official based at St Thomas; and several foreign practitioners. This geographically diverse and respected faculty ensures that the program has readily available expertise to meet its foreign law requirements.

The Program's substance courses are: Principles of International Taxation; Tax Treaties; Offshore Financial Centers; Anti-Avoidance; Anti Money-Laundering; Transfer Pricing; Law of Trusts and Entities; Tax of Trusts and Entities; International Estate Planning; International Tax Planning; Intellectual Property; and E-commerce: Business, Law, and Tax.

Each of the Program's twelve substantive courses is presented in fourteen to sixteen separate modules over a period of sixteen weeks, ending with a final examination. Each course is a comparative multi-jurisdictional review of the course's topics. Though the Program is based in the United States, the United States tax regime does not play any more significant role than other OECD and non-OECD States (and dependent jurisdictions of States) in the courses. The Program cannot serve as a substitute for a US tax program.

This Program's materials are designed using the Instructionist and Constructionist approaches. That is, each module has a formalistic textbook style presentation accompanied by a less formalistic learner-oriented study guide presentation. The study guide orients the student and breathes life into the textbook materials through horizontal thoughts not covered in the text materials, sometimes through hypothetical case studies and sometimes through jurisprudential analysis. Also, the study guide frequently contains assignments requiring from one to five hours of work including required or further research opportunities. Finally, each module has a tutorial-lecture component written more like a spoken classroom lecture, containing leading questions for the module's weekly chat. The sixteen asynchronic, weekly discussions in each course's discussion ('chat') room build on the course's modules as well as diverge into other Contextualist-applicative topics. A weekly discussion is sometimes supplemented with audio recorded 'streaming lectures' 37 .

Law Lecturer John Fairhurst states that there are 'many different taxonomies of educational objectives which are used to distinguish categories of teaching activity' and

\footnotetext{
${ }^{37}$ In the 2001-02 academic year, the Program will experiment with asynchronic and synchronic streaming video to supplement the weekly chat rooms. In the past, technological difficulties on the recipient side have limited the use of streaming audio. The technological difficulties have arisen for recipients in jurisdictions with low modem speed and/or bandwidth connection.
} 
that 'no taxonomy could truthfully claim to cover everything' (Fairhurst, 2000 at section 5.2.3). The taxonomy he presents includes (Id):

- Orientation - providing a structure for learning

- Delivery - presentation of materials

- Elaboration - clarification based on student needs

- Feedback - individual assessment and elaboration

- Diagnosis - assessment for grading

- Evaluation - assessment for remediation

- Motivation - justification of the activity, and

- Pedagogy - electronic delivery.

This taxonomy is a good starting point for a review of the program's teaching activities of

- Materials with hyperlinks

- Internet lectures and interactivity

- Internet student group interactivity

- Interactivity with other students one-on-one, and

- Email one-on-one contact with the professor.

\subsubsection{Authoring Original Materials and Editing Licensed Materials with Hyperlinks} (see Staudt, 1999)

On the whole, each module covers more than one topic and is a building block for future modules. Frequently, topics are covered and revisited from different perspectives over several modules. The teaching objective is partly to force a student away from rote memory application by re-addressing issues from several perspectives. Also, it presents a gradual peeling of the layers of the subject matter, allowing different levels of thought to occur through mediating time.

The study guides and tutorial lectures contain several questions. Some questions require short answer. The answer to which is provided nearby in order for the student to selfgauge comprehension. Some questions require answering directly in the classroom, while others require answers to be emailed directly to the professor. Sometimes the materials provide for research exercises in which case the output must generally be first sent to the professor, and then the professor provides the combined data into the classroom with comments. Most of these assignments require the use of external resources. 
Regarding the professor's use and control of external resources, the most powerful tool from the C\&IT arsenal is hyperlinking. Hyperlinking allows the professor to guide the student through datasets of resources. Hyperlinking provides instantaneous access to vast datastores (enabling search and navigation using a variety of techniques), provides interactive branching, allows access to potentially infinite information sources and 'remembers' its semantic trail.

Hyperlinks allows students to link over the window being read on the screen, workbook or tutorial sections to numerous primary informational sources. Instant, convenient access to full text sources encourages students to explore and become increasingly familiar with the true raw material of the law rather than the precooked, pre-digested versions found in the ubiquitous casebooks (Widdson, 1995). Materials may be compared side-by-side in open windows on the screen. An Internet distributed textbased lecture using hyperlinking in and of its own cannot produce deep learning. (Jones and Scully, 1996). However, such a lecture with hyperlinking may promote the student to interact with the lecturer's ideas and analytic process. Hyperlinked datasets have a special capacity to stimulate independent' learning (Paliwala, 2001).

Typically, a study guide includes problem based learning approach skills: problem and issue recognition and problem solving through research. Hyperlinks lead to independent websites for students to research other original sources ${ }^{38}$.

\subsubsection{Academic Interaction}

Each course module has two forms of interactivity: questions within the material and seminar and seminar-style Internet chat rooms.

Within the materials, the professor poses questions to students. These questions relate to that which was just read. Students answer these questions by emailing their response to the professor individually. This type of interaction allows a student to be his own competition as he is not privy to other student responses as in a typical, physical classroom setting ${ }^{39}$.

The seminar-style lecture with email-based chat room uses comparative student comments from professor questions. The classroom also presents an easy forum to present model student answers to the professor's textual questions. Students often debate answers with one another and present interesting facts.

Each student on average poses two emails weekly to a professor. The required response time spent on each email is highly divergent. Most emails are in response to the questions in the materials or in the classroom. The professor must mark the assignment, and email back comments. The professor may then accumulate the responses into a general classroom comment on the assignment.

\footnotetext{
${ }^{38}$ Often students will find independent sites on their own and share these in the classroom. Of course, one site often leads to another and research and learning are thereby enhanced.

${ }^{39}$ Within the Program's infancy, students help to create the best methods of delivery. In this case, students requested that questions also be posted in a separate Assignment category. By presenting the questions in this manner as well, students could better judge the level of work required for that module and thereby adjust their schedules.
} 
Some emails though are fact pattern questions. These emails take considerably more time to answer because frequently research and thought is required to answer. My experience is that the professor must be prepared to answer these types of questions, which take about six hours or longer of preparation time. Ignoring or throwing these questions back into the classroom each time results in the students participating less and having less respect for the professor's knowledge of the subject matter. The best comments that I receive from students are when I answer these fact patterns in an understandable manner, showing my research techniques that worked and those that failed, the thought process behind my answer, and alternative answers or facts scenarios. Generally, I follow up with a variant on the pattern for the students to think about.

\subsubsection{Creating Internet Lectures with Interactivity}

Computer technology allows rapid and easy transfer of textual and graphic data unlike typical classroom lectures. Hyperlinks create trails from educational text to original resources, further facilitating deep learning. Within legal lectures, hyperlinks allow 'asides' of full legal texts where needed. Where an individual student is already familiar with a topic, he may choose to read only the lecture. Alternatively, a student may link to the full text of an original source, glossing ${ }^{40}$ the full text with the tutorial and his notes.

In order to create Internet lectures with interactivity, a professor first may record then transcribe his or her classroom lectures. In editing the transcriptions, the professor should critically examine the P-2-S interaction that occurs in the classroom, including trains of thought, logic paths taken, and topics requiring further explanation but for time available. Then the professor may create hyperlink trails to external resources, with or without accompanying assignments, as explained in 8.1 above.

\subsubsection{Internet Student Group Discussion Creates More Interactivity}

Professor Saxer states that a significant disadvantage of an Internet delivered program is that the professor will not have the opportunity to transfer 'intellectual, professional, and ethical values' to the student (Saxer, 1999-2000, para. 32). But most law schools first year courses enroll too many students for a professor to allow frequent free discussion of topics. The residential 'seminar style' lecture employed for some niche subjects does provide an intimate discussion interface among students and the professor. Generally in a seminar style lecture, a small number of students participate to complete assignments in collaboration with the group. However, the seminar style course is a small portion of the student's law education experience.

\footnotetext{
${ }^{40}$ Glossing refers to the method employed by the earliest law students in which they would annotate copies of the Justinian Code for pedagological purposes. Hyperlinks provide a similar method for the contemporary student. A current student has greater access to examples and text via the Internet than previous students. With this capability, a student can create his own glossary of text and links enabling efficient access to references. As future practitioners, these individuals will have more access to law and international comparisons than ever before.
} 
Professor Johnson states that a 'classroom free' teaching model only presents minimal opportunity for group interactions ${ }^{41}$. Consider that in residential programs most S-2-S interface occurs in small study groups outside the classroom, if it occurs at all, from which the greater portion of the class' other members cannot participate or learn from ${ }^{42}$. Thus, at best, most S-2-S interactivity is limited to the homogenous four to six member study group of which the student is a member his or her three years ${ }^{43}$.

Internet communication allows efficient seminars to occur pursuant to the convenience of each participant. With the use of an Internet asynchronic seminar, one student can pose a question or conduct research at midnight and her classmate may respond at 7AM. Another important factor satisfied by the Internet seminar is that each student may ask a question or questions of the professor each seminar week, each student may receive a response from both the professor and fellow classmates, and all the students may review and counter respond, furthering the enquiry. Every interaction is memorialized for legacy review during the semester. Side discussion may be held under different threads, subject headed to promote quick decision making in relation to time constraints of whether to read or not as opposed to participating in another side discussion. Thus, an Internet based seminar may effectuate efficient use of time, produce more interaction for P-2-S and S-2-S, allow 'out of the study group box' cross pollination of discussion, and provide legacy review.

The University of New Mexico School of Law presented one of the earliest examples of a US law school employing Internet based group interaction in a niche tax law course (Widdison and Schulte 1998). In its Internet based Indian tax law course, each student was assigned a number of Indian tax law cases to brief. These briefs were then forwarded to the other students in the class via email. Additionally, groups of two to four students were assigned real problems in conjunction with actual pending cases. Students relied heavily on Internet-based databases such as Westlaw ${ }^{\circledR}$ and LexisNexis ${ }^{\circledR}$ to research the problems. Students were encouraged to work together on research; however, each was required to submit an individual memo. Memos were circulated via email so that each student had all pertinent case notes and memoranda. Students became more interested in sharing knowledge and learning than necessarily competing against each other through the use of this method.

This type of niche tax seminar is particularly conducive to email/Internet format. First, non-resident students may participate in order to create a broad class size in what may normally be too limited a geographical audience because of the niche subject matter (Saxer 1999-2000, at para. 31). Second, much of a student's learning in this seminar occurs in self-study: reading, research, and analytical writing. Although a class meeting could facilitate a measure of understanding regarding the various assignments, for the reasons cited above, a web-based forum would allow more student interaction.

\footnotetext{
${ }^{41}$ Johnson 2000, at 111. The ABAs Principles for distance learning stress the importance of group learning in law school, stating: 'During a law school education a student is expected to participate in a learning community...Students... learn from each other by inquiry and challenge, review and study groups.

${ }^{42}$ See Terry, 2001, see also Donahoe, 2000, at para. 63. 'Lecture is not very effective for the active learner, even lectures in which the students seem to participate. Students today cannot sit passively and listen to a lecture, even if they raise their hands to ask or answer questions. Usually the same few students answer the questions while the others take notes to actively learn later through study groups'. ${ }^{43}$ This statement is of a generalized nature, meant to include the majority of students' experience.
} 
The strongest disagreement toward the 'interactive' nature of Internet based discussion rooms come from professors that did not 'grow up' with 'instant messaging'. But more likely than not, today's J.D. and Masters student lives by e-mail and has favorably experienced interactive chat groups (Donahoe 2000, at para. 70). The Internet has a democratizing effect regarding biases based on age, race, sex, and strength of personality, favoring only the persuasive written argument. (Donahoe, 2000, at para. 70; Saxer, 1999-2000, at paras. 24 and 26).

\subsubsection{Interactivity and Written Skills Through Email Based Contact}

Even in traditional university residential settings, students and professors are taking full advantage of email communication. E-mail is 'a way of academic and professional life'. Email is the fastest and least expensive means of exchanging written communication. Small group projects, law seminars and a variety of other educational applications can be effectively and efficiently used through Internet communications using the carbon copy (cc) email facility and chat rooms simultaneously.

This educational medium has unique advantages for legal education such as the potential for enabling writing skills and enabling more student/professor interaction. In their undergraduate study, students have learned by the traditional method of stimulation through human presence, directed oral speech, behavioral speech as well as through written text. This teaching methodology carries through to legal education. One of the strongest arguments presented in favor of the Socratic case method is that it teaches future lawyers to think on their feet.

However, in practice, the lawyer spends far more time in the legal field using research skills, writing skills, and deep analytical skills, than using oral skills. By example, a day in court is preceded and followed by substantially more numerous hours of research and drafting documents as well as analyzing and creating arguments. Needing to use the 'Thinking on one's feet' skill may be indicative of too little time spent using the research, written and analytical skills required to prepare the issues.

The Internet offers a distinct advantage as the standards for written communication fundamentally differ from spoken or face-to-face communication. Without non-verbal conveyances such as intonation and gesturing, written communication must be clear and concise. Written communication evokes no immediate response and thus requires diligent care to ensure clear, concise, and complete communication. The Professor may judge with harsher standards submitted written comments as opposed to oral spontaneous remarks.

\subsubsection{Social Interaction}

Social interaction is a key component to any education. In the Internet forum, students are required to post social biographies as well as professional biographies. These documents force students to evaluate their professional focus and to choose which social aspects to include. Networking occurs based on the various expertises in fields and social interests. Students have built email relationships ${ }^{44}$ with each other and have

\footnotetext{
${ }^{44}$ Since the world of International Taxation often requires professionals to maintain a full travel itinerary, students have been known to post travel schedules in order to rendezvous with classmates who either 
strongly bonded with the professors. On average, students send a social email every other week to the professor. One clear comment is that most students want to actually meet with each other as a group once during the program and also to have the professor available for that meeting, whether it is in a formal lecture setting or a relaxed workshop.

Also, St. Thomas University School of Law requires that students and all adjunct (nonresident) faculty attend a one-week seminar-style training workshop during the beginning of the first semester of the program. This workshop focuses on the use of the delivery system (BlackBoard), on the use of the library's resources including its Internet based research databases, and on various pointers for the program of study. During this week, each morning, afternoon, and evening a social program is executed so that program participants may bond. Addressed during the symposium of the week of October 1-7, 2000 and October 7 - 12, 2001 were basic on-line computer training and computer research, a series of lectures by the non-resident and resident faculty, basic law school administrative matters as well as important networking 'get to know' each other social activities in Miami among students, professors, and administration.

\subsection{Stated Learning Goals for the Program}

\subsubsection{Knowledge-and Insight-Based Objectives}

The on-line LL.M program of St. Thomas is dynamic, in-depth, challenging, and cutting edge and has in its focus several substantive goals, which are, to assimilate a sound knowledge of basic international taxation principles in addition to acquire a sound knowledge of general international tax planning principles, including being able to deduce and tabulate the general characteristics of national tax systems in a comparative manner, and to be able to identify and evaluate principles and factors that will influence the calculation of international tax burdens. Further goals include, the comprehension of both specific and general anti-avoidance rules and principles employed by governments, and to distinguish between allowable and disallowed transactions, as well as to understand the substantive and tax law regarding various entities and to differentiate among the legal relationships of parties involved therein. Also to facilitate the student to acquire a working knowledge of international taxation planning tools presently in use and to develop continuous-learning update and research methods.

\subsubsection{General Application-Based Objectives}

In addition to the goals above, once finished with the program, the graduate will have acquired a multitude of skills needed to generally and practically apply the knowledge including the ability to design an international business plan mitigating the global tax cost, to calculate the global tax burden in terms of a return on investment, be able to draft efficient checklists to counteract international tax planning risks and to draft riskreturn choices, be able to deploy diagnostic tax matrices, in order to compare the essential characteristics of national tax systems, identifying anomalies within national systems, to collaboratively work across borders with a diverse team of role players in an

live in the destination or will be passing through. This sort of networking proves invaluable in a field where so much expertise is required in so many jurisdictions. 
effective manner and avoid and/or mitigate the circumstances of conflict between a tax authority and taxpayer

\subsubsection{Personal Utilization-Objectives}

Finally, the graduate will have acquired the ability to construct a personalized, practical, and efficient framework to collect and manage international tax data effectively; be able to determine the necessary data that must be accumulated concerning a scenario before commencing with an international tax business plan; devise a vertically and laterally integrated international tax business plan for an accumulated set of data, optimizing international tax tools and strategies, effectively avoiding anti-avoidance regulations and hedging against tax planning risks; validate practical case studies regarding the implementation of both specific anti-avoidance legislation and variant application of general anti-avoidance rules and make a scientific and functional contribution to the discipline of international taxation via researched course presentations and a welldocumented and considered thesis in the field.

\section{Part 4: Time Frame for Development of the Program and a Review of Internet Delivered Courses That Came Before}

\subsection{A Time Line for the Acceptance of Internet Based Law Programs by the American Bar Association and Southern Association of Colleges and Schools}

\subsubsection{Time Line of the Development of the St Thomas University School of Law Internet-delivered Masters Degrees}

November 1996 - A Virginia based School of Law contacted William Byrnes, an international tax lecturer, regarding the development of an on-line international tax program based on the part-distance learning program curriculum that he was teaching in South Africa.

With support by Kluwer International Law and Tax, a division of Walters Kluwer Academic Publishers, commencement of a two year restructuring of the curriculum and creation of materials for the legal and accountancy education market. The Sovereign Group, a leading supplier of offshore corporate services, provided corporate sponsorship and industry expertise for the development process.

Performed marketing study with several multinational professional firms to determine market needs.

Coordinated team of professionals to develop and test materials.

February and March, 1997 - Materials were presented to the Virginia University School of Law administration of, faculty names, and the marketing report.

May 6, 1997 - ABA issues Memorandum D9697-59, Distance Education Temporary Guidelines. 
February, 1998 - Submitted to that School of Law, sample materials of the text materials and study guides for use in the application to the ABA for acquiescence of an on-line delivered LLM. James P. White, Consultant on Legal Education to the American Bar Association proved a favorable audience for the application.

Spring, 1998 - The ABA performed a site visit at that School of Law's facilities and those of the new LLM program. It reported that the proposed LLM program would 'add' to and benefit the resources of the law school.

August 1998 - The American Bar Association's General Assembly voted in favor of the application by the School of Law to offer the Internet delivered LL.M. degree.

October 1998 - The Southern Association for Schools and Colleges (SACS) conducted their on-site visit. Professor William Byrnes presented the materials and online learning format to the SACS team.

Spring of 1999 - The ABA performed its normal on-site accreditation visit of that School of $\mathrm{Law}^{45}$. One extra member reviewed the on-line LLM program exclusively. Professor William Byrnes presented the LLM program materials, software, and a hard copy, totaling approximately 2,000 pages, of all Spring semester communications with students (including email and $\mathrm{e}^{*}$ classroom). The ABA report cited no deficiencies in the on-line $\mathrm{LLM}^{46}$.

\subsubsection{St. Thomas University's School of Law Application for ABA Acquiescence of its On-line LLM and Masters}

The St Thomas School of Law filed an application for ABA acquiescence to offer an on-line LLM and Masters in March 2000. After the ABA site visit, it signaled that acquiescence would be granted. Thus in June 2000, St Thomas School of Law notified SACS that St Thomas would, in October, begin offering the Program.

\subsection{Other US ABA/AALS Law School Distance Learning Courses $^{47}$}

\subsubsection{School of Law at the College of William and Mary ${ }^{48}$}

In 1994, Professor Trotter Hardy of the College of William \& Mary School of Law (Virginia) taught a seminar law course which employed an email mailing list. The seminar concerned a collaborative effort for drafting a constitution for a fictitious

\footnotetext{
${ }^{45}$ A law school is first provisionally accredited by the American Bar Association during which time the ABA site team evaluates the school annually. Once a law school has been fully accredited by the ABA, a site team is sent out once every seven years for the normal accreditation visit.

${ }^{46}$ In fact, one of the site team members, Professor Richardson R. Lynn, , Dean of Pepperdine School of Law, commented in a recent interview that he considered the LL.M program to be of high quality.

${ }^{47}$ See Widdison \& Schulte 1998 for an in-depth discussion of these programs). Also see two new online programs: Franklin Pierce Law Center Education Law Institute (ELI):

http://www.edlaw.fplc.edu/index.edlaw.html and Nova Southeastern University School of Law http://www.nsulaw.nova.edu/mhl/. Several newly developed online programs will be introduced in 2002. ${ }_{48}$ The College of William and Mary, founded in 1693, is the second oldest educational institution in the US. Although Harvard began operation first, William and Mary's antecedents actually predate those of the Massachusetts institution. The College is the only U.S. institution to have a Royal Charter.
} 
country. Participant communication occurred only via email discussion. Following the success of this seminar, Professor Hardy taught another seminar course with an email list format. The email mailing list format is similar to that applied by the ABA in its committee discussion lists.

Based on his personal contacts, a few non-Virginia resident students enrolled in Hardy's class. The non-resident students also registered for an independent study at their respective home schools and received a tutor faculty member from their home school. Students worked on papers through their study.

In an interview, Professor Hardy commented of his hopes to offer more Internet based courses $^{49}$.

\subsubsection{The University of New Mexico Law School ${ }^{50}$}

The University of New Mexico Law School instituted a hybrid Internet course in 1996 taught by Professor Scott A. Taylor ${ }^{51}$. The course was Indian Law (Widdison and Schulhte, 1998). The course was a traditional contact lecture course already offered by New Mexico. However, the course enrolled non-resident students who received emailed class lecture notes produced by an onsite classmate. The offsite students undertook the same learning tasks required of the onsite students, and performed research at their home institutions. One unusual aspect of this course was that offsite students participated in the contact lectures by instructing onsite classmates to present their researched case studies. Professor Taylor and a professor from the offsite student's home institution jointly performed course and project evaluations.

The University of New Mexico faculty has mixed feelings about pursuing web-based law courses. The School of Law is in the process of offering a web-based tax course ${ }^{52}$.

\footnotetext{
${ }^{49}$ With Professor William Byrnes at William \& Mary, November 1999.

${ }^{50}$ Created in 1889, the University of New Mexico opened its doors in June 1892. The University of New Mexico School of Law was founded in 1947 and received ABA accreditation in 1948. For more information see the University website: http://www.unm.edu.

${ }^{51}$ Scott A Taylor, see profile. Taylor teaches primarily in the areas of taxation and Indian law. His Indian law work includes taxation in Indian Country and Indian Gaming and these courses include a substantial number of Native American law students. His Taxation in Indian Country course was the first law school course taught over the Internet and included students from the states of Arizona, Wisconsin, Michigan, California, Washington, Kansas, and Montana, in addition to one student from Canada. Scott has served as a visiting professor at New York Law School (1986-87, 1991) and at the University of California at Davis Law School (1998-99), where he taught a variety of tax courses. During 1987-88 he served as the Professor-in-Residence in the Chief Counsel's Office of the Internal Revenue Service in Washington, D.C. In June 1999, Scott began a five-year term on the Navajo Tax Commission, which is a five-member body appointed by the Navajo Nation President and confirmed by the Navajo Nation Council.

52 These are comments made by an ABA site team member from the University of New Mexico, after evaluating the Regent Law LL.M program. A segment of St Thomas' faculty also has similar mixed feelings.
} 


\subsection{Other Non-US Law School Internet-Based Courses}

\subsubsection{Universitat Des Saarlandes ${ }^{53}$}

German Professors, Dr. Maximilian Herberger and Dr. Helmut Rußmann, developed a solely on-line, bilingual (German/ English) law course at the Universitat Des Saarlandes ${ }^{54}$. The course consisted primarily of group work, supplemented by individual assignments. Communication between participants was consummated via email, along with on-line conferences and discussion platforms (for a total of 2 hours per week).

The course was successfully organized into five phases. Phase 1 was an introductory phase to teach technical functionality and allow student introductions while Phases 2 and 3 provided further coverage of Internet and search functions. Phase 4 presented the implementation of an evaluation process of web-based legal tools and finally, Phase 5 consisted of the Incorporation of Internet-based legal discussion ${ }^{55}$.

5.3.2 Australian Taxation Studies Program (Smith and Walpole, 1998).

Australian tax professors Alan Smith and Michael Walepole developed the Australian Taxation (ATAX) Studies Program to accommodate the vast changes occurring within the Australian system of taxation. In their own words, this 'ATAX' program was organized:

'to be an innovative synthesis of distance education and campus based study, designed to cater to the needs of decentralized students in the workforce and to deal with problems of a demanding and rapidly changing discipline' (Id).

'The ATAX design is based on the theory that a successful distance education program must be premised on that which 'constitutes good teaching (Ramsden 1990).

Good teaching includes: the value of dialogue (Holmberg 1989), the three-dimensional theory of distance education with the learner, dialogue and structure (Moore 1989) and the notion that deep learning occurs when concepts are reconstructed rather than simply accepted (Parer 1994)'. ATAX, comprised of four programs (under, and post-graduate; part, and full-time), emphasizes self-directed research - including relevant research skills, and critical understanding of the Australian Tax System.

Rather than the most financially attractive or most technologically advanced delivery system, ATAX employs the most appropriate technologies. Furthermore, ATAX designers expressed the extreme importance of utilizing the most readily available and

\footnotetext{
53 The Universitat Des Saarlandes was founded in 1948 with French support. The University maintains a special relationship with France though its two campuses are located in Germany (Saarbrucken and Homburg). Currently there are 18,000 students and 270 professors. The Law and Economics department hosts the European Institute and focuses on the field of information technology (Computers and Law / Computer Science in Economics). For more details see the university web site: http://www.uni-sb.de.

${ }^{54}$ Professors Dr. Maximilian Herberger and Dr. Helmut Rußmann have developed the 'Internet Project' which encompasses such topics as World Coverage of Civil Procedure, Cyberbanking Law, and the Law of E-Commerce in Germany. Visit the web site at http://www.jura.uni-sb.de/english/.

55 The study guides developed by Professor William Byrnes also used this approach.
} 
accessible technologies. Targeting a particular student, ATAX relies more heavily upon standard audio and visual media, than on the Internet ${ }^{56}$. ATAX is exploring new Internet options that include electronic tutorials, teacher/student conferencing and more audio and visual options via more advanced computer/Internet technology.

The technology point expressed by the ATAX creators is noted. One of the difficulties of an Internet program that accepts students globally is addressing the students' regional Internet infrastructure capabilities. By example, many North American students are linked to the Internet through cable modem or DSL, whereas students from other jurisdictions may only have the infrastructure capacity to link by a $56 \mathrm{~K}$ modem.

\section{Conclusion}

One of the most difficult tasks regarding the development of a US based Internet delivered Masters program's will be the discussion of its pedagogy. The discussion of its pedagogy will require the examination of the usefulness of the Socratic method compared to the alternative methods reviewed herein ${ }^{57}$. The most cited arguments in favor of the Socratic method will be that it forces students to perform the outside case briefings and at least a few times in the semester, forces the students to think on their feet as if before a judge. However, solace may be found in that several prominent US legal academics do argue, albeit for varying reasons, for using alternative methods and approaches even in graduate (J.D.) level legal education. Though the factors of time and class size (see Hawkins-Leon, 1998, at 10, see also Thiemann, 1998, at 26). may not apply to an Internet delivered program, an academic arguing for implementation of alternative methods and approaches may find support in the emerging movement in UK legal education.

My opinion is that Masters level legal education requires a diversity of equally employed methodologies and approaches and that the Socratic method can only be but one of those methods. My opinion may be biased by my experience of international tax practice on global cross-border issues: using diverse teams comprised of attorneys that I would not meet face-to-face, to advise clients that I would not meet face-to-face. My opinion may be further biased in that I have spent significant time pursuing legal studies outside the United States, and also pursued Civil law studies along side Common law. Finally, my opinion is biased in that my seven years of teaching has been at the Masters level, generally to students more experienced in the field than myself.

My problem-solving international tax practice experience leads me to accept the goals of 'bridging the gap' legal education offered by Davis and Steinglass, Hawkins-Leon and Kerper. My seven years of teaching experience and prior educational experience leads me to accept Thiemann's application of 'inclusive' low anxiety feminist pedagogy in my classroom in order to create an environment of diverse discussion.

I also agree with the pragmatic arguments offered by Professor Nicolas Terry, that online legal education is not only inevitable, but in fact already here in the United States

\footnotetext{
${ }^{56}$ It must be noted that at the onset of this program, the Internet was not readily available or easily accessible by most students in the target markets. However, ATAX did make use of computer/electronic resources for circulation of a weekly Bulletin. ATAX also provides 'University Dial-up service' for this purpose.

${ }^{57}$ For an argument in favor of the complete overthrow of the Socratic Case method, see Moskovitz, 1992.
} 
since 1998 as it has been in Europe (Terry, 2001, at 99). The two questions I ponder are: Which US State will break ranks first in accrediting an institution offering an online Juris Doctorate graduate level degree based on providing low cost, open learning, legal education to all? Will a U.S. News \& World Report tier one institution, because it can, or tier four institution, because it must, be the first to seek such accreditation?

Regarding the value of activities performed online, in this article, depending on whether you read it either printed or online, you may have the ability to hypertext the citations to the source materials. Some academics reading online, if hypertext in this article is not available, may pursue my citations using Westlaw or a general WWW search engine like Yahoo. But to test your feelings about using online teaching activities, ask yourself the following:

- If you had hypertext to all the source materials, that the links would open in separate windows as normally so in my Internet delivered text and tutorial materials (e.g. how Westlaw works), would you have been (much) more likely to hyperlink to those sources?

- Are there issues herein that, as you read this article, you would have liked to have commented upon immediately in an interactive discussion group?

- Would you like to be able to address comments to both US and European academics, receiving feedback and pursuing discussion?

\section{References}

American Heritage Dictionary of the English Language ( $\left.4^{\text {th }} \mathrm{Ed}\right),(2000)$.

Bateman, P (1997), Toward Diversity in Teaching Methods in Law Schools: Five Suggestions from the Back Row 17 Quinnipiac 1. rev. 1997, 397, 402.

Blackie, J, (1998), The Delict Game: Learning Through Disputing over the Internet, Using the Internet to Teach Law Seminar, CTI Law Technology Centre, 22 June 1998 <http://www.law.warwick.ac.uk/seminars/98-2-jb.html>.

Cavers, D F (1943), In Advocacy of the Problem Method, 1943 Colum. L. Rev. 449, 4551943.

Cramton, R (1979) Lawyer Competence: The Role of the Law Schools, 1979 ABA. Sec. Legal Educ. \& Admissions to the Bar.

Dale, J (1998), Making the Best Use of the Internet, CTI Law Technology Centre Seminar, 22 June 1998, <http://www.law.warwick.ac.uk/seminars/98-2-jd.html>.

Davis, P C and Steinglass, E E (1997), A Dialogue About Socratic Teaching, 1997, 23 NYU Rev. L. \& Soc Change. 249, 250.

Donahoe, D R (2000), Bridging the Digital Divide Between Law Professor and Law Student, 2000, 5 VA. J.L. \& Tech. 13 (2000) at para. 62, $<$ http://www.teachinglaw.com>. 
Fairhurst, J (2000), Huddersfield's Electronically-Delivered PgDL (CPE) Course, Part Two, Journal of Information, Law and Technology (JILT) 2000 (3) <http://elj.warwick.ac.uk/jilt/00-3/fairhurst.html/>.

Frank, J (1951), Both Ends Against the Middle, 1951, 100 U. Pa. L. Rev. 20.

Hawkins-Leon, C G (1998), The Socratic Method-Problem Method Dichotomy: The Debate Over Teaching Method Continues, BYU. Educ. \& L.J, 1998, 1, 10.

Herberger and Dr. Helmut Rußmann, 'Internet Project' web site at $<$ http://www.jura.uni-sb.de/english/>.

Johnson, S (2000), 'www.lawschool.edu: Legal Education in the Digital Age, Wis. L. Rev. 2000, 85, 87.

Jonassen D and Reeves T (1996) 'Learning with Technology: Using Computers as Cognitive Tools' in Jonassen, D (ed) Handbook of Research on Educational Communications and Technology, New York, Macmillan, $693-719$.

Jones, R and Scully, J (1996), Hypertext Within Legal Education, Journal of Information, Law and Technology (JILT), 1996(2)

<http://elj.warwick.ac.uk/jilt/cal/2jones/>.

Kerper, J (1998), Creative Problem Solving vs. The Case Method: A Marvelous Adventure in Which Winnie-The-Pooh Meets Mrs. Palsgraf, 34 Cal. W. L. Rev. 1998, 351.

MacCrate, R (1992), Narrowing the Gap, Legal Education and Professional Development--An Educational Continuum, ABA. Sec. Legal Educ. \& Admissions to the Bar, 1992.

Mayer, J (1999), Alternative Futures, Journal of Law School Computing, 1999, Volume 1, Number 1.

Moskovitz, M (1992), Beyond the Case Method: It's Time to Teach with Problems, 42 J. Legal Educ. 1992, 241.

Oberst, M A (1996), Teaching Tax Law: Developing Analytical Skills, 46 J. Legal Educ. 1996, 79.

Paliwala, A (1998), Integrating Internet-Based Teaching and Learning into Legal Education, CTI Law Technology Seminar, June 1998 <http://www.law.warwick.ac.uk/seminars/98-2-ap.html>.

Paliwala, A (2001) Learning in Cyberspace, Journal of Information, Law and Technology (JILT) 2001 (1) <http://www.law.warwick.ac.uk/jilt/01-1/paliwala.html>.

Saxer, S R (1999-2000), One Professor's Approach to Increasing Technology Use in Legal Education, 6 Rich. J.L. \& Tech. 21, Winter 1999-2000. 
Shiels, R (1996), Law Students and Hypertext: One Law School's Model, Journal of Information, Law and Technology (JILT) 1996 (3).

<http://elj.warwick.ac.uk/jilt/bileta/1996/3shiels/default.htm>.

Sheppard, S (1997), Casebooks, Commentaries and Curmudgeons: An Introductory History of Law in the Lecture Hall, 82 Iowa L. Rev. 1997, 547, 556.

Smith, A and Walpole, M (1998), The Australian Experience of the Use of Selected Technology in the Delivery of a Legal Education Program - Some Lessons for Faculties and Educational Program Planners, The Journal of Information, Law and Technology (JILT), 1998 (1) <http://elj.warwick.ac.uk/jilt/98-3/smith.html>.

Staudt, R W (1999), In Search of the Origins of the Electronic Casebook, Journal of Law School Computing, Vol. 1, No. 1, 1999, history of the electronic casebook.

Taylor, S A. Professor of Law, B.A., 1973, M.A., 1978, J.D., 1978, University of New Mexico; LL.M., 1982, New York University, profile at University of New Mexico University of New Mexico Faculty Profile. 〈http://www.unm.edu >

Terry, N T (2001), Bricks Plus Bytes: How 'Click-And-Brick' Will Define Legal Education Space, 46 Vill. L. Rev. 95, 99, 2001.

Thiemann, S (1998), Beyond Guinier: A Critique of Legal Pedagogy, 24 NYU. Rev. L. \& Soc. Change 1998, 17, 26.

Widdison R and Schulte R (1998), Quarts into Pint Pots? Electronic Law Tutorials Revisited, , The Journal of Information, Law and Technology (JILT) 1998 (1), <http://elj.warwick.ac.uk/jilt/cal/98_1widd/>.

Williams S H (1993), Legal Education, Feminist Epistemology, and the Socratic Method, 45 Stan. L. Rev. 1993, 1571, 1572. 